\title{
A novel MAGED2 variant in a Chinese preterm newborn with transient antenatal Bartter's syndrome with 4 years follow-up
}

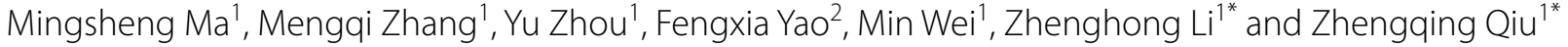

\begin{abstract}
Background: Transient antenatal Bartter's syndrome caused by MAGED2 mutation is a rare X-linked recessive renal tubular disorder. Cases reported are mostly infants, and the long-term prognosis of the disease is still under investigation.

Case presentation: We encountered a preterm male infant with polyhydramnios, polyuria, salt loss, hypercalciuria, nephrocalcinosis and alkalosis. Antenatal Bartter's syndrome was suspected, but these clinical symptoms surprisingly disappeared after about 2 months. This led to the clinical diagnosis of transient antenatal Bartter's syndrome. Gene analysis in this patient disclosed a novel variant (c.1598C > T, p.Ala533Val) in exon 12 of MAGED2 gene, and his mother was a heterozygous carrier. This patient was followed up in clinic for 4 years without recurrence of imbalance of potassium, sodium and chloride. His height and weight were in normal range, and all laboratory examinations and nephrotic ultrasound were also normal.
\end{abstract}

Conclusions: We reported the first Chinese case of transient antenatal Bartter's syndrome caused by MAGED2 mutation. The 4-year follow-up of our case further demonstrates the benign prognosis of the disease and indicates that early recognition of this phenotype could avoid unnecessary treatments.

Keywords: MAGED2 gene, Transient antenatal Bartter's syndrome, Polyhydramnios, Case report

\section{Background}

Antenatal Bartter's syndrome is an inherited disorder, characterized by polyuria, failure to thrive, hypokalemia, metabolic alkalosis, hyperreninemia and renal salt wasting which need lifelong fluid and electrolyte supplementation as well as nonsteroidal anti-inflammatory drugs. Some severe cases show mental retardation. The defective chloride transport in the loop of Henle leads to fetal

\footnotetext{
*Correspondence: worldlizhengh@outlook.com; zhengqingqiu33@aliyun. com

${ }^{1}$ Department of pediatrics, Peking Union Medical College Hospital, Chinese Academy of Medical Sciences \& Peking Union Medical College, No 1, Shuaifuyuan, Dongcheng District, Beijing 100730, China

Full list of author information is available at the end of the article
}

polyuria resulting in severe hydramnios and premature delivery.

However, some case reports described male infants' antenatal Bartter's syndrome spontaneously resolved within several weeks after birth [1]. Laghmani et al. identified a genetic cause of this transient antenatal phenotype, MAGED2 mutations by whole-exome sequencing of the suspected X chromosome [2]. The transient antenatal Bartter's syndrome patients present with polyhydramnios, prematurity and renal salt tubular function, but these clinical manifestations disappeared completely in a few months after birth. Most patients reported were infants, and the long-term influence on kidney function was still unknown [3].

We identified a novel variant (c.1598C > T, p.Ala533Val) in MAGED2 by next generation sequencing in a Chinese 
preterm neonate with transient antenatal Bartter's syndrome phenotype. This patient was followed up in clinic for 4 years with regular test of kidney function and ultrasound.

\section{Case presentation}

A previously healthy 31-year-old G1P0 woman presented with polyhydramnios at 22 weeks (amniotic fluid volume $11.5 \mathrm{~cm}$, normal value $<8 \mathrm{~cm}$ ) which led to a preterm delivery of a male infant at 29 weeks. The boy weighed $1480 \mathrm{~g}$ (P85) and was $38.5 \mathrm{~cm}$ (P50) long with head circumference $26.5 \mathrm{~cm}$ (P61). Polyuria (mean $5.8 \mathrm{ml} / \mathrm{kg} . \mathrm{h}$ ) was observed immediately after birth. Dehydration and rapid weight loss (decrease 25\% at the fourth day after birth) followed. Persistent hyponatremia, hypokalemia, hypochloremia $\left(\mathrm{Na}^{+} 129 \mathrm{mmol} / \mathrm{L}, \mathrm{K}^{+} 2.95 \mathrm{mmol} / \mathrm{L}\right.$, $\mathrm{Cl}^{-} 94 \mathrm{mmol} / \mathrm{L}$ ) necessitated intravenous fluid infusion and supplemental electrolytes. Elevated levels of renin and angiotonin (PRA1 $>12 \mathrm{ng} / \mathrm{ml} / \mathrm{h}$, normal value range $0.05-0.79 \mathrm{ng} / \mathrm{ml} / \mathrm{h}$, AT-II $1>800 \mathrm{pg} / \mathrm{ml}$, normal value range $16.2-64 \mathrm{pg} / \mathrm{ml}$ ) were noted. Severe hypercalciuria was identified by the ratio of Urine calcium:creatinine, which was $1147.8 \mathrm{mg} / \mathrm{g} \mathrm{Cr}$, and it further caused medullary nephrocalcinosis. Metabolic alkalosis progressively developed (maximal $\mathrm{pH} 7.521, \mathrm{BE} 7.8 \mathrm{mmol} / \mathrm{L}$, $\left.\mathrm{HCO}^{-} 31.1 \mathrm{mmol} / \mathrm{L}\right)$. The magnesium level in blood remained normal. Fortunately, he passed hearing screening by Otoacoustic emissions (OAE) and Auditory brainstem response (ABR). There was no positive family history for those symptoms.

Antenatal Bartter's syndrome was suspected. He was treated with parenteral nutrition containing $\mathrm{Na}^{+}$(maximum $4 \mathrm{mmol} / \mathrm{kg}$, adjusting according to the concentration of $\mathrm{Na}^{+}$) and $\mathrm{K}^{+}$(maximum $4.4 \mathrm{mmol} / \mathrm{kg}$, adjusting according to the concentration of $\mathrm{K}^{+}$) until 21 days after birth. And then, oral $15 \% \mathrm{KCl}$ solution $(2 \mathrm{ml}$, three times per day, reduced gradually 3 weeks later), and spironolactone $(2 \mathrm{mg} / \mathrm{d})$ were given for about 1 month. All symptoms gradually relieved. Neonatal polyuria normalized within 4 days, and metabolic alkalosis disappeared after 1 month. After 2 months, serum electrolyte maintained normal without oral supplemental. Renin and angiotonin level also decreased to normal (PRA1 $0.79 \mathrm{ng} / \mathrm{ml} / \mathrm{h}$, AT-III $82.33 \mathrm{pg} / \mathrm{ml}$ ) and kidney ultrasound showed improvement of medullary nephrocalcinosis. He weighed $3890 \mathrm{~g}$ (P40) and was $53 \mathrm{~cm}$ (P51) long with head circumference $35.5 \mathrm{~cm}$ (P53) at corrective gestational age of 42 weeks. Then, this patient was evaluated in clinic every 12 months. In the most recent follow-up when he was 4 years old, his height was $106.4 \mathrm{~cm}$ and weight was $15.8 \mathrm{~kg}$. Complete blood test and kidney function tests were normal ( $\mathrm{Hgb} 122 \mathrm{~g} / \mathrm{L}, \mathrm{Na} 138 \mathrm{mmol} / \mathrm{L}, \mathrm{K}$
$4.0 \mathrm{mmol} / \mathrm{L}, \mathrm{Cl} 103 \mathrm{mmol} / \mathrm{L}$, creatine $31 \mu \mathrm{mol} / \mathrm{L})$. kidney ultrasound revealed normal kidney size and structure.

A congenital nephropathy gene panel including genes of classic and antenatal Bartter's syndrome (270 genes listed in supplemental Table 1) was used to detect the pathogenic mutation. Genomic DNA was extracted from peripheral blood leukocytes of this patient and his parents according to the standard protocols for sequencing. On analysis of MAGED2 gene, a variation(c.1598C $>\mathrm{T}$, p.Ala533Val) detected by Next generation sequencing was confirmed by Sanger sequencing analyses (Fig. 1). This patient is hemizygous and his mother was a heterozygous carrier.

\section{Discussion and conclusions}

In antenatal Bartter's syndrome, five different genes are found to be responsible: SLC12A19 (type I), KCNJ1 (type II), $B S N D$ (type IV), CLCNKA, and CLCNKB (type IVb) [4]. Clinical manifestations include polyhydramnios, prematurity, polyuria, and renal salt wasting. Sensorineural deafness is also a manifestation of antenatal Bartter's syndrome type IV and IVb. Treatment of lifelong electrolyte supplementation and nonsteroidal anti-inflammatory drugs is needed.

In May 2016, MAGED2 was defined to be responsible for transient antenatal Bartter's syndrome. MAGED2 is located in Xp11.2 which is a hot spot for X-linked mental retardation (XLMR) and encodes melanoma-associated antigenD2 (MAGE-D2). MAGE-D2 is expressed universally in normal tissues and participates in cell cycle regulation. It protects cells from apoptosis [5]. This gene has been proven participating in development of breast cancer and melanoma and may be a promising biomarker for gastric cancer [6-8]. Laghmani et al. found MAGE-D2 also expresses in the distal tubules in kidneys and promotes NKCC2 and NCC expression through adenylate cyclase and cAMP signaling and a heat-shock protein [2]. Recent study reveals that MAGED2 mRNA and protein are significantly upregulated in tubular cells in human kidney injury, which indicates MAGED2 plays a role in tubular cell injury during acute kidney disease [9].

Most patients reported were infants, and the longest follow-up was 17 years with normal glomerular and tubular function [2]. All symptoms disappeared spontaneously during follow-up, but the mechanism of transient character of the disease is not clear. Two hypotheses were made by Laghmani et al. [2]. First, beyond a certain stage of renal development, MAGED2 is not needed for the expression of NKCC2 and NCC because of the increased sensitivity of adenylate cyclase activity to vasopressin. In addition, postnatally higher levels of oxygenation in the kidney may promote the synthesis of NKCC 2 and NCC [10]. 


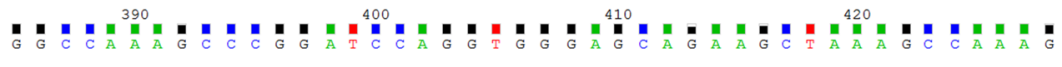

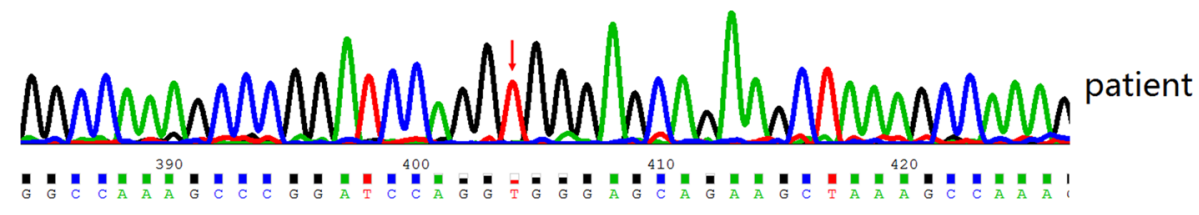

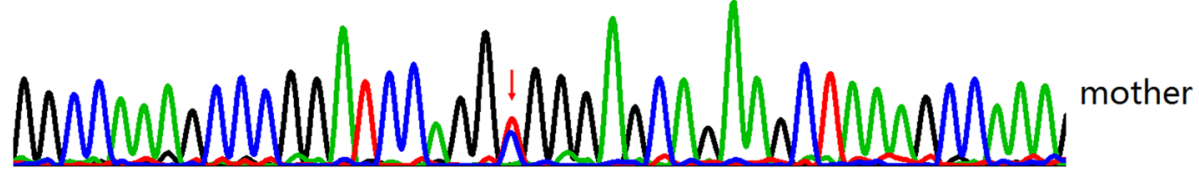 \\ G G C C C

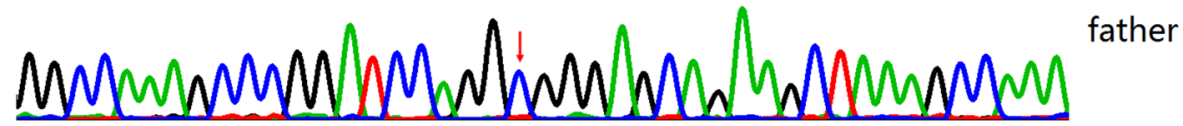 \\ MAGED2 (NM_201222): c.1598C>T(p.Ala533Val)}

Fig. 1 Sanger sequencing of MAGED2 gene in proband and family member. Blood samples were collected from the patient as well as his parents, and sequenced. Mutated MAGED2 gene (c.1598C > T) was found in the patient 1 while his mother was a heterozygous carrier for that mutation

Various kinds of mutations associated with transient antenatal Bartter's syndrome including nonsense, frameshift, splice-site mutations, missense and in-frame deletion, were identified and reported [2, 3, 11]. In this patient, a missense mutation was present. The variation, c. $1598 \mathrm{C}>\mathrm{T}$ locates in exon 12 of the MAGED 2 gene. It predicts a change from an alanine codon to a valine codon. This variant was not found in the 1000 Genomes (http://1000genomes.org/) and Exac (http://exac.broad institute.org/), suggesting that it was not likely to be a Single Nucleotide Polymorphism (SNP). Polyphen-2 software was used to further evaluate the possible deleterious consequence of the novel MAGED2missense variant, and the p.Ala533Val substitution was predicted to be possibly damaging with a score of 0.780 which suggest the novel variant would substantially alter the function of protein. The results of multiple amino acid sequence alignment showed that the novel p.Ala533Val variant occurred at a highly evolutionarily conserved residue. Further study is needed to reveal the subsequent protein structure and functional change.

In this patient, diagnosis was made based on the transient clinical manifestations of antenatal Bartter's syndrome. The differential diagnosis of this Bartter-like phenotype is other known types of antenatal Bartter's syndrome (types I, II, IV, and IVb). According to the clinical manifestations of 13 patients with transient antenatal Bartter's syndrome described by Laghmani et al., polyhydramnios appeared in second trimester of pregnancy, which was earlier than other known types of antenatal Bartter's syndrome. All 13 patients with transient antenatal Bartter's syndrome were preterm caused by polyhydramnios [2]. Polyuria lasted about 3 days to 6 weeks and ended at 30 to 33 weeks of gestational age. This phenotype is probably life threatening because of dehydration according to the reported cases. Bartter's syndrome types I, II, IV, and IVb are associated with similar manifestations like polyhydramnios, prematurity. But polyuria, hypokalemia, and metabolic alkalosis persist and need lifelong treatment [12]. However, after 4-year follow-up in our hospital, our patient did not show any relapse of this diseases, suggesting a favorable prognosis of transient antenatal Bartter's syndrome if the patient received carefully supporting treatment during the acute phase of this disease. Thus, we highlight the importance of early recognition of transient antenatal Bartter's syndrome for saving lives as well as avoiding unnecessary and potentially harmful indomethacin treatment.

In conclusion, we report here the first Chinese case of transient antenatal Bartter's syndrome and a novel $M A G E D 2$ gene alteration. Gene analysis is recommended for preterm infant with prenatal severe polyhydramnios, postnatal polyuria and hypokalemia. Our 4years followup of the patient further demonstrates a favorable prognosis of the disease and thus, early recognition of this transient disease helps to avoid unnecessary treatments. 


\section{Abbreviations}

ABR: Auditory brainstem response; OAE: Otoacoustic emissions; MAGE-D2: melanoma-associated antigen D2; XLMR: X-linked mental retardation.

\section{Supplementary Information}

The online version contains supplementary material available at https:/doi. org/10.1186/s12882-021-02553-1.

\section{Additional file 1.}

\section{Acknowledgements}

Many thanks to the patient and his parents.

\section{Authors' contributions}

MS M and MQ Z drafted the manuscript. Y Z and ZH L clinically evaluated and managed the patients medically. FY and M W carried out the molecular genetic testing as well as analysis. ZQ Q critically revised the final manuscript for important intellectual content and approved it. All authors read and approved the final manuscript.

\section{Funding}

National Key Research and Development Project of China (2016YFC0901500 and 2016YFC0905102), which supports genetic test.

\section{Availability of data and materials}

A congenital nephropathy gene panel including genes of classic and antenatal Bartter's syndrome (270 genes listed in supplemental Table 1) for next generation sequencing was used to detect the pathogenic mutation. The primers and conditions for thermal cycling, and the datasets used during the study are available from the corresponding author on reasonable request.

\section{Declarations}

Ethics approval and consent to participate

Ethical no: ZJS-1248. Approved by the Institutional Review Board of Peking Union Medical College Hospital (PUMCH). Written informed consent was obtained from the mother

\section{Consent for publication}

Written informed consent was obtained from parents for the publication of all personal information contained in this case report.

\section{Competing interests}

None.

\section{Author details}

'Department of pediatrics, Peking Union Medical College Hospital, Chinese Academy of Medical Sciences \& Peking Union Medical College, No 1, Shuaifuyuan, Dongcheng District, Beijing 100730, China. ${ }^{2}$ Laboratory of Clinical Genetics, Peking Union Medical College Hospital, Chinese Academy of Medical Sciences \& Peking Union Medical College, Beijing, China.

Received: 19 February 2021 Accepted: 10 October 2021

Published online: 11 December 2021

\section{References}

1. Reinalter S, Devlieger H, Proesmans W. Neonatal Bartter syndrome: spontaneous resolution of all signs and symptoms. Pediatr Nephrol. 1998;12(3):186-8. https://doi.org/10.1007/s004670050433.

2. Laghmani K, Beck BB, Yang SS, Seaayfan E, Wenzel A, Reusch B, et al. Polyhydramnios, transient antenatal Bartter's syndrome, and MAGED2 mutations. N Engl J Med. 2016;374(19):1853-63. https://doi.org/10.1056/ NEJMoa1507629.
3. Legrand A, Treard C, Roncelin I, Dreux S, Bertholet-Thomas A, Broux F, et al. Prevalence of novel MAGED2 mutations in antenatal Bartter syndrome. Clin J Am Soc Nephrol. 2018;13(2):242-50. https://doi.org/10 2215/CJN.05670517.

4. Alfandary $\mathrm{H}$, Landau D. Future considerations based on the information from Barrter's and Gitelman's syndromes. Curr Opin Nephrol Hypertens. 2017:26(1):9-13. https://doi.org/10.1097/MNH.0000000000000285.

5. Barker PA, Salehi A. The MAGE proteins: emerging roles in cell cycle progression, apoptosis, and neurogenetic disease. J Neurosci Res. 2002;67(6):705-12. https://doi.org/10.1002/jnr.10160.

6. Pirlot C, Thiry M, Trussart C, Di Valentin E, Piette J, Habraken Y. Melanoma antigen-D2: a nucleolar protein undergoing delocalization during cell cycle and after cellular stress. Biochim Biophys Acta. 2016;1863(4):581-95. https://doi.org/10.1016/j.bbamcr.2015.12.010.

7. Tseng HY, Chen LH, Ye Y, Tay KH, Jiang CC, Guo ST, et al. The melanomaassociated antigen MAGE-D2 suppresses TRAIL receptor 2 and protects against TRAIL-induced apoptosis in human melanoma cells. Carcinogenesis. 2012;33(10):1871-81. https://doi.org/10.1093/carcin/bgs236.

8. Kanda M, Nomoto S, Oya H, Takami H, Shimizu D, Hibino S, et al. The expression of melanoma-associated antigen D2 both in surgically resected and serum samples serves as clinically relevant biomarker of gastric Cancer progression. Ann Surg Oncol. 2016;23(Suppl 2):S214-21. https://doi.org/10.1245/s10434-015-4457-8.

9. Valino-Rivas L, Cuarental L, Agustin M, Husi H, Cannata-Ortiz P, Sanz AB, et al. MAGE genes in the kidney: identification of MAGED2 as upregulated during kidney injury and in stressed tubular cells. Nephrol Dial Transplant. 2019:34(9):1498-507. https://doi.org/10.1093/ndt/gfy367.

10. Quigley R, Saland JM. Transient antenatal Bartter's syndrome and X-linked polyhydramnios: insights from the genetics of a rare condition. Kidney Int. 2016;90(4):721-3. https://doi.org/10.1016/j.kint.2016.07.031.

11. Yang K, Huo X, Zhang Y, Zhang M, Gao Y, Wu D, et al. Genetic analysis of a pedigree affected with Bartter's syndrome. Zhonghua Yi Xue Yi Chuan Xue Za Zhi. 2019;36(7):701-3. https://doi.org/10.3760/cma.j.issn.10039406.2019.07.011.

12. Koulouridis E, Koulouridis I. Molecular pathophysiology of Bartter's and Gitelman's syndromes. World J Pediatr. 2015;11(2):113-25. https://doi.org/ 10.1007/s12519-015-0016-4.

\section{Publisher's Note}

Springer Nature remains neutral with regard to jurisdictional claims in published maps and institutional affiliations.
Ready to submit your research? Choose BMC and benefit from:

- fast, convenient online submission

- thorough peer review by experienced researchers in your field

- rapid publication on acceptance

- support for research data, including large and complex data types

- gold Open Access which fosters wider collaboration and increased citations

- maximum visibility for your research: over 100M website views per year

At BMC, research is always in progress.

Learn more biomedcentral.com/submissions 